\title{
Audiological issues and hearing loss among Veterans with mild traumatic brain injury
}

\author{
Michael Oleksiak; ${ }^{1-2 *}$ Bridget M. Smith, PhD; ${ }^{1-2}$ Justin R. St. Andre, MA; ${ }^{1}$ Carly M. Caughlan, AuD; ${ }^{3}$ Monica \\ Steiner, $\mathbf{M D}^{4}$ \\ ${ }^{1}$ Department of Veterans Affairs (VA) Center for Management of Complex Chronic Care, Spinal Cord Injury Quality \\ Enhancement Research Initiative, Edward Hines Jr VA Hospital, Hines, IL; ${ }^{2}$ Stritch School of Medicine, Program in \\ Health Services Research, Loyola University Chicago, Maywood, IL; ${ }^{3}$ Audiology and ${ }^{4}$ Physical Medicine and Rehabil- \\ itation, Edward Hines Jr VA Hospital, Hines, IL
}

\begin{abstract}
We examined the prevalence, severity, etiology, and treatment of audiology problems among Operation Iraqi Freedom/Operation Enduring Freedom (OIF/OEF) Veterans with mild traumatic brain injury (TBI). A retrospective chart review was performed of 250 Veterans with mild TBI. Results of a comprehensive second-level mild TBI evaluation and subsequent visits to audiology were evaluated. We found the vast majority (87\%) of Veterans reported some level of hearing disturbance and those involved in blast injuries reported a higher incidence of hearing disturbance than those with other injury etiologies. Audiology referrals were given to 75 Veterans and 37 attended. At this visit, Veterans reported tinnitus (75.7\%) and hearing loss (59.8\%). Nearly half (48.6\%) of Veterans were diagnosed with conductive hearing loss, sensorineural hearing loss, or central auditory dysfunction. An additional 24.3\% of Veterans had subclinical levels of auditory dysfunction. Our study has highlighted the increased prevalence of hearing loss among OIF/OEF Veterans and, thus, the need for appropriate referrals and treatment. Strategies to address perceived stigma associated with hearing loss may increase attendance at follow-up visits. Additionally, while only a third of audiograms were found to be abnormal, advanced testing resulted in a significant percentage of our population being diagnosed with auditory dysfunction.
\end{abstract}

Key words: adult, audiology, auditory dysfunction, blast injuries, brain injuries, hearing, hearing loss, mTBI, tinnitus, Veterans, wounds and injuries.

\section{INTRODUCTION}

A dramatic increase in the use of explosive devices in Operation Enduring Freedom and Operation Iraqi Freedom is responsible for a significant shift in the types of injuries experienced among soldiers. Between 2003 and 2005, 68 percent of combat injuries were blast related [1]. Head and neck injuries have increased in proportion relative to previous conflicts, and 78 percent of these injuries were consequential to explosions caused by devices such as improvised explosive devices (IEDs), land mines, mortars, bombs, or grenades [2]. Mild traumatic brain injury (TBI) can result from these types of blast-related injuries [3], and their prevalence in modern

Abbreviations: $\mathrm{C} \& \mathrm{P}=$ Compensation and Pension, $\mathrm{CAP}=$ central auditory processing, CAPD = central auditory processing disorder, $\mathrm{dBHL}=$ decibels hearing loss, $\mathrm{DPOAE}$ = distortion product otoacoustic emission, IED = improvised explosive device, NSI = Neurobehavioral Symptom Inventory, OAE = otoacoustic emission, $\mathrm{RPG}=$ rocket-propelled grenade, $\mathrm{SD}=$ standard deviation, $\mathrm{TBI}=$ traumatic brain injury, VA = Department of Veterans Affairs, VHA = Veterans Health Administration.

*Address all correspondence to Michael Oleksiak, Edward Hines Jr VA Hospital, Research Service, 5000 South 5th Ave (151H), Hines, IL 60141; 708-202-2414; fax: 708-2022316. Email: MichaelOleksiak@gmail.com http://dx.doi.org/10.1682/JRRD.2011.01.0001 
combat has increased dramatically. An estimated 20 percent, or 300,000 of the 1.6 million soldiers deployed to Iraq and Afghanistan, have mild TBI [4]. Individuals with mild TBI can present clinically with cognitive, physical, or behavioral problems [5]. Individuals also often present with complaints of anxiety, depression, apathy, and mood swings [5].

In conjunction with the increase in mild TBI, blastrelated injuries also result in auditory and vestibular issues. Because the human ear is designed to be sensitive to changes in pressure, it is the most susceptible organ to damage from the pressure created by a blast wave [6] Previous studies have found that 62 percent of blastrelated TBI patients admitted after the onset of Operation Iraqi Freedom complained of hearing loss and 38 percent reported tinnitus [7]. Hearing problems were also found to be present in TBI patients who had not experienced a blast, with 44 percent complaining of hearing loss and 18 percent reporting tinnitus [7]. A study of 12,521 Veterans with TBI found that 34.6 percent of the cohort selfreported auditory impairment and an additional 9.9 percent reported both auditory and visual impairment. Of these, Veterans who experienced blast-related injuries were found to have the highest rate of self-reporting both auditory and visual impairment [8].

Ear and hearing injuries may significantly affect the daily lives of soldiers, both in and out of combat. Permanent hearing loss has been reported to contribute to psychosocial and physical health problems, such as depression, decreased social and emotional function, personal relationships, and decreased cognitive function [911]. While studies have examined the link between TBI and hearing loss, the mild TBI population specifically has not been widely studied. A previous study of 36 American adults with a history of mild TBI found that when compared with the normative values, these individuals performed significantly worse on the Dichotic Word Listening Task [12]. Additionally, more than one-third of individuals with a mild TBI were found to fail at least one condition of a dichotic word recall task [13]. However, these studies do not include information about clinical testing and results.

\section{METHODS}

A retrospective chart review of 250 Veterans with mild TBI was performed at a single, midwestern Depart- ment of Veterans Affairs (VA) medical center. Individuals with a confirmed diagnosis of mild TBI between June 15 , 2007, and July 15, 2009, were identified by local physicians based on TBI reports to the Veterans Health Administration (VHA) Support Service Center and considered for inclusion. Patients with moderate/severe TBI, a prior history of ear disease or hearing loss, or non-VA care for hearing loss were excluded.

Veterans with mild TBI and hearing problems were identified using the VA's comprehensive second-level TBI evaluation. Veterans are referred for a comprehensive second-level evaluation after receiving an initial positive mild TBI screening. The initial screening is administered by a healthcare provider and consists of four questions regarding exposure to a mild TBI event(s), immediate symptoms, and current symptoms. Further information regarding the VHA's mild TBI screening process is described by Donnelly et al. [14]. The comprehensive TBI evaluation [14-15] is designed to identify the presence or absence of mild TBI and examines items such as demographics, injury etiology, number and degree of blasts exposed to, distance from blasts, and the Neurobehavioral Symptom Inventory (NSI) [16]. The NSI consists of 22 TBI symptoms, including hearing difficulty, and asks patients to rate the degree to which the symptom disturbs them. Items are rated on a 5-point scale ranging from "not at all" $(0=$ none: rarely if ever present; not a problem at all) to "almost always" (4 = very severe: almost always present and I have been unable to perform at work, school, or home due to this problem; I probably cannot function without help). Degree of blasts consists of primary, secondary, tertiary, and quaternary blast injuries. Primary blast injuries consist of pressure waves created by the blast. Secondary injuries are due to penetrating trauma caused by shrapnel. Tertiary blast injuries are the result of people being thrown into the ground or a fixed object. Quaternary injuries are any illness or disease not due to primary, secondary, or tertiary causes (e.g., burns, crush injuries, toxic inhalation) [17].

Detailed data were collected from electronic medical records by using a data collection tool developed for this study. Information was extracted from the comprehensive second-level TBI evaluation and from subsequent referrals to audiology (including all audiology follow-up appointments). Data elements collected from the medical record of audiology encounters included family history, demographics, hearing complaints, number of visits, noise 
exposure, examinations received, diagnoses, and treatment. Degree of hearing loss was measured as decibels hearing loss (dBHL) on an audiogram, where any threshold above $25 \mathrm{dBHL}$ at any frequency was considered a hearing loss. Furthermore, 26-40 dBHL was mild, 41-54 dBHL was moderate, 55-69 dBHL was moderately severe, 70-89 dBHL was severe, and $90 \mathrm{dBHL}+$ was profound. Abnormal findings for tympanometry were considered \pm 100 daPa middle ear peak air pressure, $<0.3 \mathrm{~mL}$ or $>1.7 \mathrm{~mL}$ for static compliance. In instances where otoacoustic emissions (OAEs) were performed, one of two methods was used. Diagnostic testing was performed with the Bio-logic Scout OAE device (Natus Medical Inc; San Carlos, California) from 750 to $8,000 \mathrm{~Hz}$ using Boys Town criteria (65 and $55 \mathrm{~dB}$ for level 1 and level 2, respectively). A screening test was performed with the Bio-logic AuDX Pro (Natus Medical Inc), from 1,500 to $6,000 \mathrm{~Hz}$. For diagnostic testing, results were deemed to be abnormal if an emission was absent at any or all frequencies. An absent response was defined as less than $6 \mathrm{~dB}$ emission to noise-floor ratio, as well as an emission amplitude greater than $-10 \mathrm{~dB}$, replicated. For screening OAEs, results were documented as either "pass" or "refer" using the default pass/refer criteria and were considered abnormal if a "refer" finding was noted at any or all frequencies, replicated. For acoustic reflex thresholds, findings were abnormal if they were unexpectedly absent or elevated based on pure tone findings. The exact central auditory tests given varied depending on the Veterans' history and report, as well as their performance throughout testing, but generally included at least one test from each of the following categories: auditory temporal processing (Random Gap Detection Test, Gaps in Noise Test), auditory temporal patterning (Pitch Pattern and Duration Pattern Sequence tests), dichotic listening (Dichotic Digits, Competing Words and Competing Sentences subtests of SCAN-A and Competing Sentences Test), monaural lowredundancy speech (low-pass filtered speech testing, QuickSIN $^{\mathrm{TM}}$ Speech-In-Noise Test, Words in Noise, Filtered Words and Auditory Figure-Ground subtests of SCAN-A), and binaural interaction (masking level difference). Speech recognition tests were most often CID-W22 recorded word lists, but sometimes may have been performed with a monitored live voice. If immittance, OAE, or central auditory processing (CAP) test findings were found to be abnormal despite the presence of normal hearing on the audiogram, a "subclinical hearing loss" designation would be given. Descriptive statistics used include chi-square for dichotomous variables and analysis of variance for continuous variables. All analyses were conducted using SAS 9.2 software (Cary, North Carolina).

\section{RESULTS}

A total of 240 patients met inclusion criteria. Of the original 250 Veterans, 1 was excluded after being identified as having moderate/severe TBI, 5 had a prior history of ear disease or hearing loss, and 4 received care outside the VA for hearing loss. A total of 75 Veterans received an audiology referral, with 37 presenting for an examination (Figure).

At the time of the comprehensive second-level evaluation, the average age of the 240 Veterans was 27.9, with 73 percent of the population under the age of 30 . The majority of Veterans were white (71.25\%), single (64.17\%) males (92.08\%) who were currently employed or a student (69.58\%) and had a high school diploma or less (62.92\%) (Table 1).

\section{Comprehensive Second-Level Evaluation}

During the comprehensive second level-evaluation, when asked to rate "hearing difficulty" (from the NSI) experienced since injury, 87 percent of the Veterans reported some degree of disturbance of daily living due to hearing difficulty (NSI greater than zero). Overall,

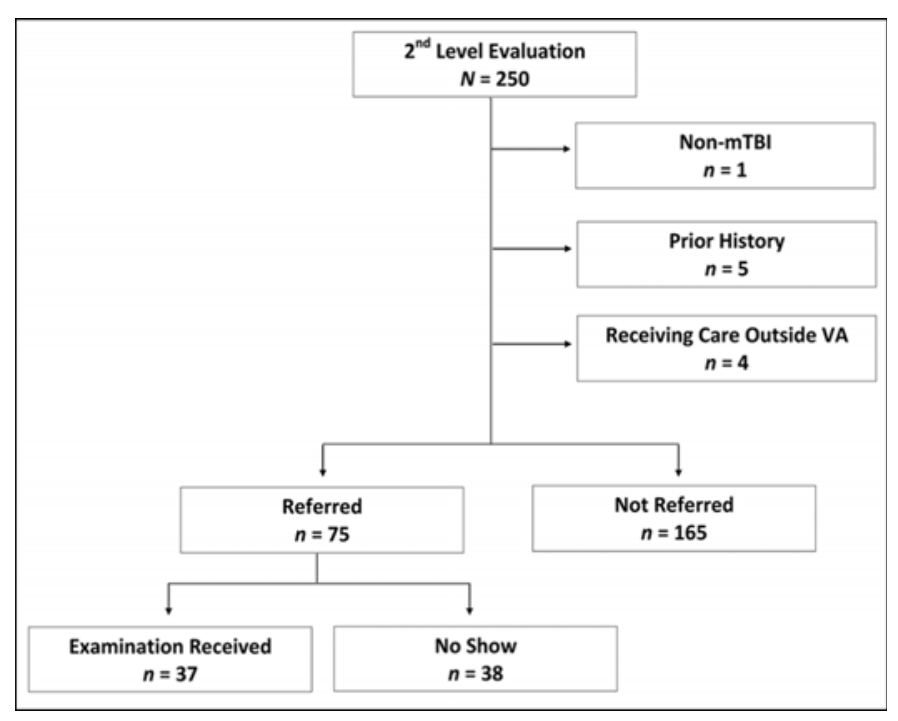

Figure.

Study cohort flowchart. $\mathrm{mTBI}=$ mild traumatic brain injury, VA = Department of Veterans Affairs. 
Table 1.

Demographics for patients overall $(N=240)$ and for those receiving hearing examination $(n=37)$. Data shown as $\%(n)$ unless otherwise indicated.

\begin{tabular}{lcc}
\hline \multicolumn{1}{c}{ Demographic } & Overall & $\begin{array}{c}\text { Hearing } \\
\text { Examination }\end{array}$ \\
\hline Age (yr) & $38.33(92)$ & $43.24(16)$ \\
$20-24$ & $34.58(83)$ & $27.03(10)$ \\
$25-29$ & $19.58(47)$ & $16.22(6)$ \\
$30-39$ & $7.50(18)$ & $13.51(5)$ \\
$40+$ & $92.08(221)$ & $86.49(32)$ \\
Sex: Male & $64.17(154)$ & $59.46(22)$ \\
Marital Status: Single & $62.92(151)$ & $70.27(26)$ \\
Education: High School or Less & $69.58(167)$ & $67.57(25)$ \\
Employed/Student & $71.25(171)$ & $81.08(30)$ \\
Race/Ethnicity: White & $1.86 \pm$ & $2.16 \pm$ \\
NSI: Hearing Difficulty & & 0.89 \\
\multicolumn{2}{l}{ (mean \pm standard deviation) } & 1.03 \\
\hline NSI = Neurobehavioral Symptom Inventory. & \\
\hline \hline
\end{tabular}

Veterans reported a moderate level of hearing difficulty disturbance (mean \pm standard deviation $[\mathrm{SD}]=1.86 \pm$ 1.0) with 40.4 percent reporting moderate, 24.2 percent reporting severe, and 3.3 percent reporting very severe difficulty. Men reported greater hearing difficulty disturbance than women (mean NSI $=1.9$ vs 1.3 , respectively; $p<0.05$ ) as did whites compared with minorities (mean NSI $=1.9$ vs 1.5 , respectively; $p<0.05$ ). No significant associations were found between age, marital status, education, or employment and reported hearing difficulty disturbance.

More than half the cohort, or 64.2 percent $(n=154)$, reported at least one blast exposure, 106 of whom were injured solely from blast injuries. Among those Veterans who were only involved in blast injuries, 78 had identified the most intense type of blast injury they experienced during the second-level evaluation as 85.9 percent primary blast $(n=67)$ and 14.1 percent secondary blast $(n=11)$. Also among Veterans only involved in blast injuries, 97 reported the type of blast they were exposed to as IED only (36.1\%, $n=35)$, rocket-propelled grenades (RPGs) only $(6.2 \%, n=6)$, bomb only $(4.1 \%, n=$ $4)$, mortar only (3.1\%, $n=3)$, or a combination of multiple blast exposures (e.g., IED and RPGs; $50.5 \%, n=49$ ).

Some level of hearing difficulty (NSI symptom score greater than zero) was reported by a greater percentage of Veterans incurring a blast-related injury (92.5\%) compared with fall $(84.0 \%)$, vehicle (80.0\%), and mixed etiology (any combination of accident types; 87.5\%) (Table 2).
However, the average NSI hearing difficulty score did not differ statistically among these groups. The average reported NSI hearing difficulty and percentage reporting hearing difficulty did not differ by degree of blast exposure (primary, secondary, tertiary) among patients incurring a blast-only mild TBI $(n=106)$ or by number of visits to audiology (Table 2).

\section{Referrals to Audiology Clinic}

Seventy-five Veterans with mild TBI (31.3\%) received referrals to the audiology clinic. Referral to audiology did not differ by age, sex, marital status, education, employment, or race/ethnicity; however, Veterans receiving a referral to audiology reported significantly more severe hearing difficulty than those not receiving a referral (2.2 vs 1.7, respectively; $p<0.01$ ). Of Veterans who indicated that they experienced hearing difficulty on the NSI (symptom score greater than zero), 34.9 percent were referred $(n=73)$ while 65.1 percent were not given a referral $(n=136 ; p<0.005)$. Examination of physician notes from the comprehensive mild TBI evaluation found hearing loss (81.3\%), balance and dizziness problems (70.7\%), tinnitus (56.0\%), and earaches (9.3\%) to be the

\section{Table 2.}

Neurobehavioral Symptom Inventory (NSI)-Hearing Difficulty: Average (mean \pm standard deviation [SD]) and percentage reporting some difficulty.

\begin{tabular}{|c|c|c|}
\hline \multirow{2}{*}{ Characteristic } & \multicolumn{2}{|c|}{ NSI-Hearing Difficulty } \\
\hline & $\overline{\text { Mean } \pm \text { SD }}$ & $\%$ Score $>1^{*}$ \\
\hline \multicolumn{3}{|l|}{ Type of Accident } \\
\hline Fall $(n=25)$ & $1.92 \pm 1.15$ & 84.00 \\
\hline Vehicular $(n=10)$ & $1.50 \pm 1.08$ & 80.00 \\
\hline Blast $(n=106)$ & $1.99 \pm 0.98$ & 92.45 \\
\hline $\operatorname{Mixed}^{\dagger}(n=48)$ & $1.83 \pm 1.04$ & 87.50 \\
\hline \multicolumn{3}{|l|}{ Greatest Degree of Blast Experienced } \\
\hline Primary $(n=67)$ & $2.09 \pm 0.98$ & 94.03 \\
\hline Secondary $(n=11)$ & $1.81 \pm 0.87$ & 100 \\
\hline \multicolumn{3}{|l|}{ Blast Type } \\
\hline Improvised Explosive Device Only $(n=35)$ & $1.71 \pm 0.99$ & 88.57 \\
\hline Rocket-Propelled Grenade Only $(n=6)$ & $2.83 \pm 0.41$ & 100 \\
\hline Bomb Only $(n=4)$ & $2.75 \pm 1.50$ & 100 \\
\hline Mortar Only $(n=3)$ & $1.67 \pm 0.58$ & 100 \\
\hline Blast Combination, All $(n=49)$ & $2.08 \pm 1.04$ & 93.88 \\
\hline Blast Combination, $2 \times(n=24)$ & $1.92 \pm 0.83$ & 95.83 \\
\hline Blast Combination, $3+(n=25)$ & $2.08 \pm 1.04$ & 92.00 \\
\hline \multicolumn{3}{|l|}{ No. of Audiology Visits } \\
\hline $1(n=32)$ & $2.10 \pm 0.91$ & 100 \\
\hline $2+(n=6)$ & $2.50 \pm 0.55$ & 100 \\
\hline
\end{tabular}


most commonly reported symptoms of those referred to audiology $(n=75)$.

\section{Evaluations in Audiology Clinic}

Of the 75 Veterans with mild TBI given a referral to audiology, 37 (49.3\%) attended. Veterans who did not attend their examination reported similar levels of hearing difficulty during the second-level evaluation as those who attended their appointments (2.18 vs 2.16 , respectively). No significant differences existed between those attending or not attending when compared by age, sex, marital status, education, employment, or race/ethnicity. However, those attending their audiology appointment had a greater number of referrals given at the time of the second-level comprehensive examination (mean $\pm \mathrm{SD}=$ $3.54 \pm 1.48)$ than those who did not attend their audiology visit (mean $\pm \mathrm{SD}=2.79 \pm 1.44 ; p<0.05$ ). Patients who did not attend were most frequently a "no-show" on one or more occasions for unknown reasons $(52.6 \%, n=$ 20). Documented reasons for not attending included a scheduled Compensation and Pension (C\&P) examination $(7.9 \%, n=3)$, appointment refusal $(5.3 \%, n=2)$, redeployment (5.3\%, $n=2)$, and cerumen buildup (2.6\%, $n=1)$. An additional nine Veterans (23.7\%) did not schedule or attend an appointment for unknown reasons.

The main complaints during the audiological examination were tinnitus $(75.7 \%, n=28)$ and hearing loss $(59.5 \%, n=22)$. Frequencies of tests performed and abnormalities are summarized in Table 3 . Of the 37 visits, audiograms were noted in the examination of 35 (94.6\%), word recognition tests in 26 (70.3\%), and CAP disorder (CAPD) tests in 6 (16.2\%). Audiogram tests resulted in abnormal findings for 12 of these Veterans (34.3\%). Tympanometry and distortion product OAE (DPOAE) examinations were both noted in 21 visits (56.8\%) and were abnormal at a rate of 23.8 percent and 81.0 percent, respectively. Additionally, acoustic reflex thresholds were noted for 11 patients (29.7\%) and were abnormal at a rate of 18.1 percent. Acoustic reflex decay was noted for one patient (2.7\%) and was not abnormal. No tympanic membrane perforations were noted.

Of the 37 Veterans who had audiology clinic visits, hearing loss occurred in varying degrees (Table 4). Veterans with abnormal findings that differed between each ear were considered to be part of the category representing the more severe level and/or form of hearing difficulty. Based on audiograms, seven Veterans (18.9\%) were found to have mild hearing loss (26-40 dB), four
Table 3.

Patients receiving specific examination types and abnormal findings $(N=37)$.

\begin{tabular}{lcc}
\hline \multicolumn{1}{c}{ Examination } & $\begin{array}{c}\text { Performed, } \\
\text { \% (n) }\end{array}$ & $\begin{array}{c}\text { \% } \\
\text { Abnormal }^{*}\end{array}$ \\
\hline Otoscopy & $32.43(12)$ & 0 \\
Audiometry & $94.59(35)$ & 34.29 \\
Tympanometry & $56.76(21)$ & 23.81 \\
Acoustic Reflex Decay & $10.81(4)$ & 0 \\
Acoustic Reflex Threshold & $18.92(11)$ & 18.18 \\
Speech Recognition Score & $70.27(26)$ & 0 \\
DPOAE & $56.76(21)$ & 80.95 \\
CAPD & $16.22(6)$ & 100 \\
\hline
\end{tabular}

${ }^{*}$ Out of tests performed.

CAPD $=$ central auditory processing disorder, DPOAE $=$ distortion product otoacoustic emissions.

Table 4.

Type and degree of hearing loss $(N=37)$.

\begin{tabular}{lc}
\hline \multicolumn{1}{c}{ Hearing Loss } & \% Affected \\
\hline Type & 27.03 \\
Normal & 27.03 \\
Sensorineural & 24.32 \\
Subclinical & 16.22 \\
Central & 5.41 \\
Conductive & 0 \\
Mixed & \\
Degree & 35.14 \\
Normal & 18.92 \\
Mild & 10.81 \\
Moderate & 2.70 \\
Moderate-Severe & 0 \\
Severe & 27.02 \\
Missing & 5.41 \\
Audiogram Not Performed & $\dagger$ \\
${ }^{*}$ Considered missing when audiogram results incomplete/missing $(n=10)$. \\
${ }^{\dagger}$ Audiogram was not performed during evaluation $(n=2)$. \\
\hline \hline
\end{tabular}

(10.8\%) moderate hearing loss (41-54 dB), and one (2.7\%) moderate-severe hearing loss (55-69 dB). Overall, 10 Veterans (27.0\%) were diagnosed as having sensorineural hearing loss, 6 (16.2\%) were diagnosed with CAPD, and 2 (5.4\%) were found to have conductive hearing loss. Furthermore, nine Veterans (24.3\%) experienced subclinical levels of auditory dysfunction.

Follow-up and treatment plans varied and were not noted for all individuals. Referrals were given to 19 (51.4\%) patients. They included 10 ear, nose, and throat referrals; 5 CAPD referrals; 3 neuropsychological testing referrals; 2 C\&P referrals; and 1 neurology referral. It 
was suggested that nine (24.3\%) patients receive a tinnitus evaluation while a hearing aid, wax removal, mental hygiene, and hearing protection were suggested for one patient each (2.7\%). Treatment plans were unavailable or undocumented in four (10.8\%) examinations.

\section{DISCUSSION}

Audiology issues are highly prevalent among Veterans with mild TBI. In our study, 87 percent of Veterans with mild TBI reported some level of hearing difficulty while more than 64 percent of Veterans reported at least a moderate level of hearing difficulty. Overall, 31.3 percent of our cohort received a referral to audiology. Of those who complained of hearing loss, 65.1 percent were not given a referral. Because of the complicated medical needs of those with mild TBI, the significant percentage of Veterans experiencing hearing difficulties may not have received a referral because more pressing issues presented at the time of their comprehensive second-level examination. Previous studies have found that in such patients, ear and balance deficits are commonly overlooked [1]. However, without a referral at this time, patients may not otherwise seek treatment. These findings highlight the need for clinicians to pay particular attention to hearing complaints among mild TBI patients and for more comprehensive screening methods and proper referral methods to be developed.

Men reported greater difficulty hearing than women. In support of this, our study found that a significantly greater percentage of men were involved in blast-related mild TBI. White Veterans were also found to report significantly greater hearing difficulty and increased percentages of hearing complaints than non-white Veterans for unknown reasons.

Of particular interest, 50.7 percent $(n=38)$ of Veterans who were referred did not attend their audiology clinic appointment. One possibility for low attendance at audiology appointments is the stigma attached to both hearing loss and hearing aids. Previous studies have found that perceived stigma has an influence on decisionmaking processes that occur during initial acceptance of hearing loss, testing, and use of hearing aids [18]. Additionally, this stigma is not exclusive to men and is perceived by younger women as well [19]. Efforts to reduce the stigma surrounding hearing loss may increase the number of Veterans who return for follow-up visits after the comprehensive evaluation. Although the effect of hearing loss on the Veteran population is lesser known, its effects in the general population and the elderly are well documented. Because hearing loss increases with aging, these Veterans may also experience symptomatic hearing loss at younger ages than expected. Conceivably, the Veteran population, with an active role both in the workplace and home life, may also experience a significant loss of quality of life because of unmanaged hearing loss. Impaired hearing may restrict both employment and recreational activity. Furthermore, the effects of hearing loss are only further compounded by the effect of mild TBI on an individual's health overall.

Unexpectedly, Veterans who did attend their audiology appointment received about 25 percent more referrals at the comprehensive second-level examination than those who did not attend. This result was not consistent with our hypothesis that patients with many health concerns may prioritize their visits. Instead, some of these patients may be more likely to visit all their appointments because they are already spending a greater amount of time at the healthcare facility.

A third of audiograms resulted in abnormal findings. We were unable to find any previous studies that examined the mild TBI population; however, our results are similar to previous studies that found TBI patients (TBI injury severity unreported) to have decreased hearing sensitivity on audiograms [7,20]. Pure sensorineural hearing loss was found to be the most common type of hearing loss among Veterans, as in previous studies [7]. While previous studies have found that tympanic membrane perforation is the most common ear-related blast injury, we found no tympanic membrane perforations in this mild TBI population [6,21].

To better assist patients, physicians need to be aware of the services that are provided by audiologists; otherwise, referrals will not be made. Close to two-thirds of the Veterans who were tested in our cohort were found to have "normal hearing” per the audiogram. Yet, the high prevalence of testing beyond the audiogram in our cohort found abnormalities in a significant number of these Veterans. DPOAE testing within our sample also produced a large group diagnosed with subclinical hearing loss. This finding suggests that blasts and other mild TBI etiologies may cause damage that is not detected by an audiogram and strongly indicates that audiological testing should not stop after the audiogram. 
Because dizziness, loss of balance, hearing complaints, sound sensitivity, and tinnitus are not only possible symptoms of TBI but also symptoms of otologic pathology, the audiologist is an important team member for management of the blast-injured and/or TBI populations [22]. Blast-related auditory deficits can occur throughout the auditory system, from the outer ear to the cortex, which can result in a variety of complex symptoms [23]. Audiologists can offer a variety of treatment and management options for audiological and vestibular dysfunction. Additionally, audiologists must be aware that although a patient who complains of hearing loss in this population may present a normal audiogram, further testing may result in identifying auditory dysfunction.

The use of additional testing, such as CAPD testing that helps to identify CAP deficits, allows for patientspecific management [22]. Once the nature and severity of specific deficits are identified, appropriate guidance for management can be offered. Education and counseling on deficit-specific compensatory and communication strategies should also be offered. Unfortunately, the results of a 2007 questionnaire given to randomly selected members of the American Academy of Audiology found that audiologists have very limited knowledge of this additional testing [24]. Hence, it is not surprising that many VA audiology clinics are not providing these services [22]. More training is needed for audiologists with regards to this type of testing, and more research is needed on CAP and management in the adult TBI population [22].

When hearing loss occurs, the VA offers premium amplification choices and has many assistive listening devices available to suit nearly all hearing impaired Veterans. In the current study, 20 percent of the Veterans with hearing loss exhibited a mild sensorineural hearing loss. Open-fit devices are ideal for mild to moderate high frequency hearing losses and are appealing to a younger population because of cosmetics and Bluetooth compatibility. For those with more severe atypical losses, many VA centers offer cochlear implants and bone-anchored hearing devices. Counseling on hearing conservation and preservation as well as various auditory training exercises may be offered. Auditory training may take several forms, including clinician-directed (Auditory Process Training), self-directed (Auditory Process Training 3), and computer-based (Listening and Communication Enhancement).

Tinnitus was the number one complaint of Veterans tested in this current study (73.7\%). Many options for tin- nitus management are currently available, including counseling, sound generators, hearing aids, and other devices. The method currently endorsed by the VA is progressive tinnitus management, developed at the National Center for Rehabilitative Auditory Research, which is located at the Portland VA Medical Center in Portland, Oregon [25-26]. This is a hierarchal program designed to be maximally efficient and address the needs of all tinnitus patients [27]. Resources for this program are abundant and free to all VA audiologists and Veterans.

Our study is limited by small sample sizes and its retrospective chart review nature. Prevalence of hearing difficulty was self-reported by Veterans during the comprehensive second-level evaluation. Thus, results may be affected by a patient's subjectivity. As previously stated, many patients diagnosed with mild TBI have several medical concerns and, for some Veterans, receiving treatment for hearing difficulties may not have been among their most crucial needs. This could have resulted in both fewer referrals and poor attendance in audiology clinic even after receiving a referral. Lastly, our study was limited by the number of Veterans who attended their audiology follow-up appointment.

It would be interesting to further compare our findings and diagnoses with those of other sites and audiology clinics, which may not perform the same level of testing. Future research may also consider comprehensively comparing testing methods by location, because this would dramatically help the progression toward a standardization of care for these individuals. A longitudinal study following this population would also be beneficial, because it may provide evidence of accelerated hearing loss in those who went undiagnosed.

\section{CONCLUSIONS}

The discovery that the vast majority (87\%) of our cohort reported some level of hearing difficulty on the NSI is an alarming indication of the prevalence of hearing issues among Veterans with mild TBI. Also notable is that the majority of Veterans who indicated hearing difficulty were involved in blast-related accidents, specifically IEDs and multiple blasts. The relatively low referral rates to audiology within the cohort elicit a need for further exploration, because hearing difficulty could result in significantly decreased quality of life. 
Hearing loss and tinnitus were commonly reported problems. We found that tympanometry and audiogram testing were often not enough to come to a complete diagnosis of the patient's ailments. In particular, DPOAE and acoustic reflex threshold examinations both produced abnormal findings in several patients considered normal after initial hearing testing. Sensorineural hearing loss, conductive hearing loss, and subclinical levels of hearing loss were prevalent among the population. We found varying treatment methods, but referrals to ear, nose, and throat and tinnitus evaluations were the most common. Further evaluation of testing methods and standardization of treatment among mild TBI patients experiencing hearing loss are needed.

\section{ACKNOWLEDGMENTS}

\section{Author Contributions:}

Study concept and design: M. Oleksiak, B. M. Smith, J. R. St. Andre, M. Steiner.

Acquisition of data: M. Oleksiak.

Statistical analysis: M. Oleksiak.

Analysis and interpretation of data: M. Oleksiak, C. M. Caughlan, M. Steiner.

Drafting of manuscript: M. Oleksiak, C. M. Caughlan.

Manuscript revision: B. M. Smith, J. R. St. Andre, M. Steiner.

Critical revision of manuscript for important intellectual content:

C. M. Caughlan.

Study supervision: B. M. Smith, J. R. St. Andre.

Financial Disclosures: The authors have declared that no competing interests exist.

Funding/Support: This study was supported by the VA Office of Research and Development, Health Services Research and Development Service (grant IIR 07-188-3).

Additional Contributions: We would like to thank Salma Ahmed and Bridget O’Brien for their assistance in the initial chart review. Mr. St. Andre is now with the Health Research and Educational Trust, Chicago, Illinois.

Institutional Review: This study was approved by the local Human Subjects Institutional Review Board.

Disclaimer: The views expressed in this article are those of the authors and do not necessarily reflect the position or policy of the VA or the U.S. Government.

\section{REFERENCES}

1. Chandler D. Blast-related ear injury in current U.S. military operations: role of audiology on the interdisciplinary team. ASHA Leader [Internet]. 2006 Jul 11. Available from: http://www.asha.org/Publications/leader/2006/060711/ $\underline{\text { f060711a2/ }}$
2. Owens BD, Kragh JF Jr, Wenke JC, Macaitis J, Wade CE, Holcomb JB. Combat wounds in operation Iraqi Freedom and operation Enduring Freedom. J Trauma. 2008;64(2): 295-99. [PMID:18301189] http://dx.doi.org/10.1097/TA.0b013e318163b875

3. Langlois JA, Rutland-Brown W, Thomas KE. Traumatic brain injury in the United States: emergency department visits, hospitalizations, and deaths. Atlanta (GA): National Center for Injury Prevention and Control; 2004.

4. Hoge CW, Goldberg HM, Castro CA. Care of war veterans with mild traumatic brain injury-flawed perspectives. N Engl J Med. 2009;360(16):1588-91. [PMID:19369664] http://dx.doi.org/10.1056/NEJMp0810606

5. Zeitzer MB, Brooks JM. In the line of fire: traumatic brain injury among Iraq War veterans. AAOHN J. 2008;56(8): 347-53, quiz 354-55. [PMID:18717301] http://dx.doi.org/10.3928/08910162-20080801-03

6. Patow CA, Bartels J, Dodd KT. Tympanic membrane perforation in survivors of a SCUD missile explosion. Otolaryngol Head Neck Surg. 1994;110(2):211-21.

[PMID:8108156]

7. Lew HL, Jerger JF, Guillory SB, Henry JA. Auditory dysfunction in traumatic brain injury. J Rehabil Res Dev. 2007; 44(7):921-28. [PMID:18075949] http://dx.doi.org/10.1682/JRRD.2007.09.0140

8. Lew HL, Pogoda TK, Baker E, Stolzmann KL, Meterko M, Cifu DX, Amara J, Hendricks AM. Prevalence of dual sensory impairment and its association with traumatic brain injury and blast exposure in OEF/OIF veterans. J Head Trauma Rehabil. 2011;26(6):489-96. [PMID:21386715] http://dx.doi.org/10.1097/HTR.0b013e318204e54b

9. Herbst KG, Humphrey C. Hearing impairment and mental state in the elderly living at home. BMJ. 1980;281(6245): 903-5. [PMID:7427503] http://dx.doi.org/10.1136/bmj.281.6245.903

10. Mulrow CD, Aguilar C, Endicott JE, Tuley MR, Velez R, Charlip WS, Rhodes MC, Hill JA, DeNino LA. Quality-oflife changes and hearing impairment. A randomized trial. Ann Intern Med. 1990;113(3):188-94. [PMID:2197909]

11. Hétu R, Jones L, Getty L. The impact of acquired hearing impairment on intimate relationships: implications for rehabilitation. Audiology. 1993;32(6):363-81. [PMID:8267527] http://dx.doi.org/10.3109/00206099309071867

12. Roberts MA, Persinger MA, Grote C, Evertowski LM, Springer JA, Tuten T, Moulden D, Franzen KM, Roberts RJ, Baglio CS. The Dichotic Word Listening Test: preliminary observations in American and Canadian samples. Appl Neuropsychol. 1994;1(1-2):45-56. [PMID:16318561] http://dx.doi.org/10.1207/s15324826an0101\&2 9

13. Richardson E, Springer J, Varney N, Struchen M, Roberts R. Dichotic listening in the clinic: new neuropsychological 
applications. Clin Neuropsychol. 1994;8(4):416-28. http://dx.doi.org/10.1080/13854049408402044

14. Donnelly KT, Donnelly JP, Dunnam M, Warner GC, Kittleson CJ, Constance JE, Bradshaw CB, Alt M. Reliability, sensitivity, and specificity of the VA traumatic brain injury screening tool. J Head Trauma Rehabil. 2011;26(6):439-53. [PMID:21386716] http://dx.doi.org/10.1097/HTR.0b013e3182005de3

15. Ruff RL, Ruff SS, Wang XF. Headaches among Operation Iraqi Freedom/Operation Enduring Freedom veterans with mild traumatic brain injury associated with exposures to explosions. J Rehabil Res Dev. 2008;45(7):941-52. [PMID:19165684] http://dx.doi.org/10.1682/JRRD.2008.02.0028

16. Cicerone KD, Kalmar K. Persistent postconcussion syndrome: the structure of subjective complaints after mild traumatic brain injury. J Head Trauma Rehabil. 1995; 10(3):1-17. [PMID:11660671] http://dx.doi.org/10.1097/00001199-199510030-00002

17. DePalma RG, Burris DG, Champion HR, Hodgson MJ. Blast injuries. N Engl J Med. 2005;352(13):1335-42. [PMID:15800229] http://dx.doi.org/10.1056/NEJMra042083

18. Wallhagen MI. The stigma of hearing loss. Gerontologist. 2010;50(1):66-75. [PMID:19592638] http://dx.doi.org/10.1093/geront/gnp107

19. Erler SF, Garstecki DC. Hearing loss- and hearing aidrelated stigma: perceptions of women with age-normal hearing. Am J Audiol. 2002;11(2):83-91. [PMID:12691218] http://dx.doi.org/10.1044/1059-0889(2002/020)

20. Basford JR, Chou LS, Kaufman KR, Brey RH, Walker A, Malec JF, Moessner AM, Brown AW. An assessment of gait and balance deficits after traumatic brain injury. Arch Phys Med Rehabil. 2003;84(3):343-49. [PMID:12638101] http://dx.doi.org/10.1053/apmr.2003.50034

21. Ritenour AE, Wickley A, Ritenour JS, Kriete BR, Blackbourne LH, Holcomb JB, Wade CE. Tympanic membrane perforation and hearing loss from blast overpressure in Operation Enduring Freedom and Operation Iraqi Freedom wounded. J Trauma. 2008;64(2, Suppl):S174-78, discussion S178. [PMID:18376162] http://dx.doi.org/10.1097/TA.0b013e318160773e
22. Myers P, Wilmington D, Gallun F, Henry J, Fausti S. Hearing impairment and traumatic brain injury among soldiers: special considerations for the audiologist. Semin Hear. 2009;30(1):5-27. http://dx.doi.org/10.1055/s-0028-1111103

23. Myers PJ, Henry JA, Zaugg TL. Considerations for persons with mild traumatic brain injury. Perspect Audiol. 2008; 4(1):21-34. http://dx.doi.org/10.1044/poa4.1.21

24. Chermak GD, Silva ME, Nye J, Hasbrouck J, Musiek FE. An update on professional education and clinical practices in central auditory processing. J Am Acad Audiol. 2007; 18(5):428-52, quiz 455. [PMID:17715652] http://dx.doi.org/10.3766/jaaa.18.5.7

25. Henry JA, Schechter MA, Zaugg TL, Myers PJ. Progressive audiologic tinnitus management. The ASHA Leader [Internet]. 2008 Jun 17. Available from: http://www.asha.org/ Publications/leader/2008/080617/f080617b.htm

26. Myers P, Henry J, Zaugg T, Kendall C. Tinnitus evaluation and management considerations for persons with mild traumatic brain injury. ASHA Access Audiology. 2009 Mar/ Apr;8(2). Available from: http://www.asha.org/aud/articles/ tinnitusTBI.htm

27. Fausti SA, Wilmington DJ, Gallun FJ, Myers PJ, Henry JA. Auditory and vestibular dysfunction associated with blastrelated traumatic brain injury. J Rehabil Res Dev. 2009; 46(6):797-810. [PMID:20104403]

http://dx.doi.org/10.1682/JRRD.2008.09.0118

Submitted for publication January 2, 2011. Accepted in revised form September 14, 2011.

This article and any supplementary material should be cited as follows:

Oleksiak M, Smith BM, St. Andre JR, Caughlan CM, Steiner M. Audiological issues and hearing loss among Veterans with mild traumatic brain injury. J Rehabil Res Dev. 2012;49(7):995-1004.

http://dx.doi.org/10.1682/JRRD.2011.01.0001

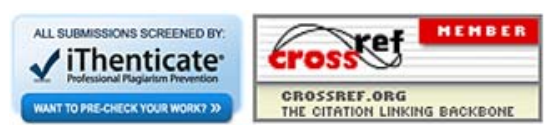


